\title{
Online Fertilizer Recommendation System (OFRS): A Step Towards Precision Agriculture And Optimized Fertilizer Usage By Smallholder Farmers In Bangladesh
}

\author{
Hossain, M.A. and Siddique, M. N. A
}

\begin{abstract}
The recent progression and Green Revolution (approx. between the 1990s-2010s) in agriculture of Bangladesh resulted in an increase of total production despite yield-gap to ensure food security. But agriculture in Bangladesh is still backedup by higher use of inputs (agrochemicals-fertilizers, pesticides; modern varieties, irrigation etc.) and inversion tillage. This conventional agrochemicalbased smallholder agriculture may lead to soil and environmental degradation, soil acidification, and a decline in soil fertility. Therefore, it is significant to optimize input application in intensive agriculture, especially fertilizers. This paper introduces the potential online facilities of generating online fertilizer recommendations for smallholder farmers in Bangladesh to ensure proper usage of fertilizers and enable sustainable agricultural production. We also highlighted how the usage of fertilizers increased with an increase in total production over time. But the sustainability of production in the years to come still remain challenging. With the aim of sustainable crop production, reduction in the misuse of fertilizers and reduction of input cost by optimizing the present pattern of excessive fertilizer application, the Soil Resource Development Institute (SRDI) provides location-specific fertilizer recommendation through both the manual and soil test based interpretation of plant nutrients: soil database in Upzazila Nirdeshika and static laboratory soil analysis. Recently, SRDI developed webbased software named Online Fertilizer Recommendation System (OFRS). The system is capable of generating location-specific fertilizer recommendations for selected crops by analyzing the national soil database developed by this governmental institute. The software requires farmer field location, respective soil and land type, and crop type and variety information to generate cropspecific instant fertilizer recommendation. It was observed that by using fertilizer according to the recommended dose calculated on the basis of soil test values, farmers could harvest approx. 7-22\% higher yield of different crops over usual farmers practice. If this system can be popularized and disseminated by effective agricultural extension, this would immensely contribute to the promotion of precision agriculture, input cost reduction and it would certainly enable us to optimize fertilizer application by the smallholder farmers in Bangladesh.
\end{abstract}

Keywords: Fertilizers, OFRS, Soil-test database, Precision agriculture.

Published Online: August 5, 2020

ISSN: $2684-446 \mathrm{X}$

DOI : 10.24018/ejgeo.2020.1.4.47

\section{A. Hossain}

Principal Scientific Officer Soil Resource Development Institute (SRDI), Ministry of Agriculture, Mrittika Bhaban, Krishi Khamar Sarak, Dhaka, Bangladesh

(e-mail: altajolly63@yahoo.com)

\section{N. A Siddique*}

Senior Scientific Officer

Soil Resource Development Institute (SRDI), Ministry of Agriculture, Mrittika Bhaban, Krishi Khamar Sarak, Dhaka, Bangladesh

(e-mail: siddique.mna@live.com)

*Corresponding Author

\section{INTRODUCTION}

The issues of current concern in South Asia as well as in Bangladesh's agriculture are deteriorating environmental quality, declining input response from major crops, and a widening gap between potential and realized farm yields. The progress in agro-technology and technological changes are the important forces that shape the agricultural economy of Bangladesh. But issues related to sustainability in land management and resource use efficiency is one of the great concern. The idea of sustainable land management with competing resources requires a clear understanding of the ecological and socio-economic consequences of alternative management actions. However, in the sole pursuit of high productivity (i.e. yield goal) during the past decades (approx.
1980-2015), the critical linkage between agriculture and the environment has been neglected resulting in agro-ecosystems with little resilience in Bangladesh. The aspects of land management and the nature of maximizing resource use for agriculture (i.e. agrochemicals, fertilizers, irrigation, highyielding varieties), may put land quality into stake rising the production cost manifold for the smallholder farmers [1], [2]. The excessive use of fertilizers may cause soil acidification and soil amendments would be necessary to rectify/ameliorate certain soil types for higher yields [3], [4]. Similar and or other forms of land and soil quality degradation [5], [6] and soil fertility decline [7] could evolve in other countries due to intensive agriculture, this is especially so in South Asia and the Pacific region, which accounts for more than $70 \%$ of the global agricultural 
population but only $30 \%$ of the world's farmland [8]. But these regions' agricultural resource use efficiency is poor, which in turn negatively affecting the agroecosystems. One of the key input resources is fertilizer which is used abundantly and inefficiently (i.e. lack of soil test based recommended fertilizer application, dose, and timing of fertilizer application) in South Asia [9]. Thus, optimization of fertilizer application by recommendation is crucial for the sustainability of agricultural systems in South Asia. In Bangladesh, fertilizer recommendation is not widely adopted since the Green Revolution (i.e. from the 90's to 2010) in agriculture, instead food security has been achieved through agrochemicals, high yielding varieties and irrigation-based agriculture [10], [2], [11].

Yield increases in Bangladesh have been achieved at considerable expenses to its resource base and largely by means of excessive and indiscriminate use of external inputs like fertilizer, irrigation, and pesticides [2]. Most fertilizer recommendation programs contain the crucial steps of collecting representative soil samples, accurate and precise laboratory analysis and using a well-calibrated fertilizer recommendation model to estimate fertilizer recommendations. It is often assumed that collecting a soil sample is trivial. This is not so but requires adequate extension support for farmers. Obtaining accurate and representative soil samples is the basic for soil-based fertilizer recommendations. A representative soil sample is one that may adequately portrays the nutrient content of the area sampled from an arable field [12]. Fertilizer prescription is characterized by the formulation of fertilizer recommendation based on crop needs at different yield targets (i.e. high yield goal, moderate yield goal) crop variety, soil fertility status, irrigation facilities, management practices and previous research results which may be expressed as follows:

Yield $=f$ (soil, crop, climate, farmers' management); where yield refers to both quality and quantity of the crop. Crop yield is a measurement of the amount of agricultural production harvested-yield of a crop-per unit of land area.

Soil is the principal supplier of plant nutrients. Plants derive 13 essential plant nutrients out of 16 from the soils. But soils vary considerably in their inherent capacities to supply nutrients which gradually decline due to intensive cropping if the nutrients are not replenished by organic and inorganic sources. Almost all upland soils are low in organic matter and deficient in $\mathrm{N}$ [13]. Availability of $\mathrm{P}$ to the crops is a problem mainly in calcareous soils of Ganges floodplain and acidic soils of terrace and hill areas. Status of $\mathrm{K}$ is not a great problem in floodplain areas, but the terrace and Piedmont soils are not capable of supplying enough $\mathrm{K}$ to the crops. Although $\mathrm{P}$ and $\mathrm{K}$ deficiencies are not severe, the addition of these two nutrients is a must for getting a higher yield. Paddy soils remain underwater during the growing period which causes unavailability of $\mathrm{S}$ and $\mathrm{Zn}$ for rice crops. Other dryland crops also face the problem of $\mathrm{S}$ and $\mathrm{Zn}$ deficiencies in many areas of Bangladesh. Boron was reported to be deficient in some regions. Magnesium deficiency was found in the coarse-textured soils of Old Himalayan Piedmont plain, Brown hill soils, and Grey floodplain soils of the northern part of the country. The Ca reserve of many floodplain soils is depleting due to the decalcification process and deficiency of $\mathrm{Ca}$ is probable in the near future. Deficiencies of $\mathrm{Cu}$ and $\mathrm{Mn}$ were reported but very rare [14], [15]. Therefore, it is essential to add nutrients to the soil through organic and inorganic fertilizers in order to get the desired yield of crops. Nowhere in the world, can high yield be secured without the use of balanced fertilizers.

Research and development in agronomy have been aimed at developing integrated farming systems with the use of machinery and balanced use of fertilizer and irrigation and less/ or no use of pesticides. Such ideas and practices can be categorized as precision agriculture and the application of the modern tool in soil fertility management and soil characterization [5], [16], [7], [17]. The technological development of satellite navigation within the last few years provides a tool for taking into consideration of variation within fields during cultivation. This has opened a new avenue in modern agriculture for location-specific fertilizer applications. Thus, Soil Resource Development Institute (SRDI) in collaboration with KATALYST (a Foreign NGO in Bangladesh) developed web-based software named Online Fertilizer Recommendation System (OFRS), which is a step towards precision agriculture for optimized fertilizer recommendation in Bangladesh. This article synthesized how the agricultural progress over decades caused the rise in gross yields and an abundance of fertilizer usage in Bangladesh. Besides we also explored the need, scope, and potential of OFRS at farmer level in Bangladesh.

\section{A. Bangladesh agricultural scenario: crop yield and need of inputs optimization}

The properties and qualities of agricultural soils and their relative position within the relief differ considerably even within small areas of arable fields in Bangladesh. These variations in local sites (i.e. can be at macro and or microscale) potentially result in non-homogenous crop stands and thereby influences the crop yields. The smallholder management can be also responsible for non-homogenous crop stand, either within fields or between fields. Variations of fertilization (i.e. rater of fertilizer amount and timing) are another important factor that drives crop yields variably in smallholder systems. However, in current agricultural practices, such site differences are not addressed properly. Farming practices are governed by average site quality (i.e. soil and land qualities). As a result, sub-parts of the fields that have high yield potentials remain underexplored whereas areas of low fertility are over-fertilized. Soil and land resources are finite natural resources that need greater attention for ensuring food security of the burgeoning population through sustainable land management.

Soil and land resources have been identified/characterized in Bangladesh through reconnaissance and semi-detailed soil surveys over decades [18]. At present, 469 Upazila (subdistrict) level 'Land and Soil Resource Utilization Guide' alias Upazila Nirdeshika is at hand for agricultural planning and development at a macro level in Bangladesh. But due to the complexity of land parceling and land use, and more importantly due to inadequate extension activities, this macro-level data is insufficient to fulfill the need of individual farmers during crop growing seasons in 
Bangladesh.

Bangladesh has made commendable progress over the past 40 years in achieving food security, despite frequent natural disasters and population growth; food grain production, for example, the production of rice over decades with respect to the area has been shown in Figure 1. It is evident that the area and production of major two rice (namely rainfed Aman and irrigated Boro rice) have increased substantially but the semirainfed Aus rice area and production have been decreased over time. With one of the fastest rates of productivity growth in the world since 1995 (averaging 2.7 percent per year, second only to China), Bangladesh's agricultural sector has benefited from a sound and consistent policy framework backed-up by substantial public investments in technology, rural infrastructure and human capital [19]. Among the major crops, the production of cereals (i.e. rice, maize, wheat), potato, and vegetables have increased manifold during the last four decades [20]. With annual population growth of 1.8 million people, Bangladesh requires approximately an additional 3.0 million metric tons of rice a year [21]. With a growing population, planning for future cereal production to meet food security challenges would require projections of future supply and demand for cereals.

The production of rice increased in Bangladesh due to the use of modern and hybrid varieties, improved agronomic management, pest, and disease control. However, the farming system still dominates by the conventional approach, which means that agrochemicals based agriculture is practiced throughout the country to meet up yield goals. This agricultural inputs especially chemical fertilizer use has been increased over time in Bangladesh (Figure 2). Therefore it is immensely important that at farmer level balanced fertilizer use should be introduced in Bangladesh without any delay. In this regard, online fertilizer recommendation has great potential, which can also reduce the input requirement of fertilizers and offset the abundance of chemical fertilizers. In addition, the reduction of fertilizer is also important for agricultural and environmental sustainability. But the demands for food can only be achieved through adequate crop diversification, minimization of yield-gap, and best management practices in rice-based systems of Bangladesh.

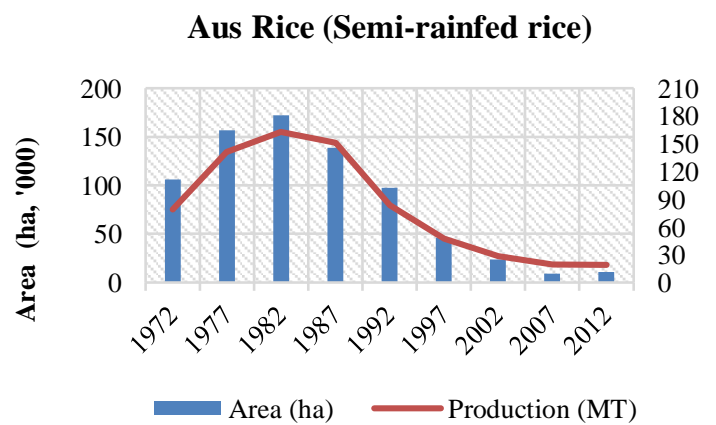

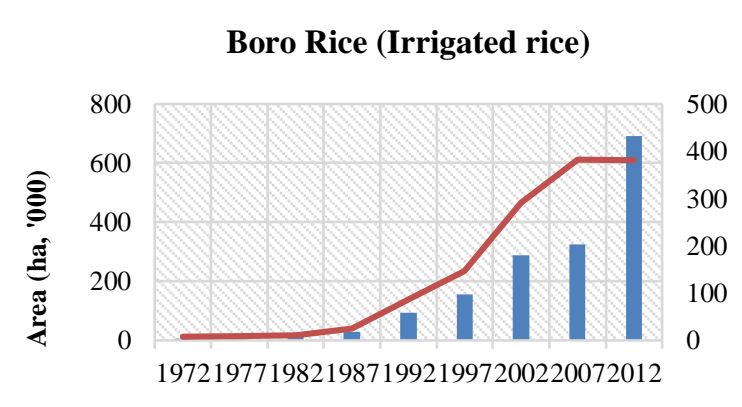

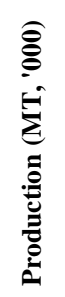

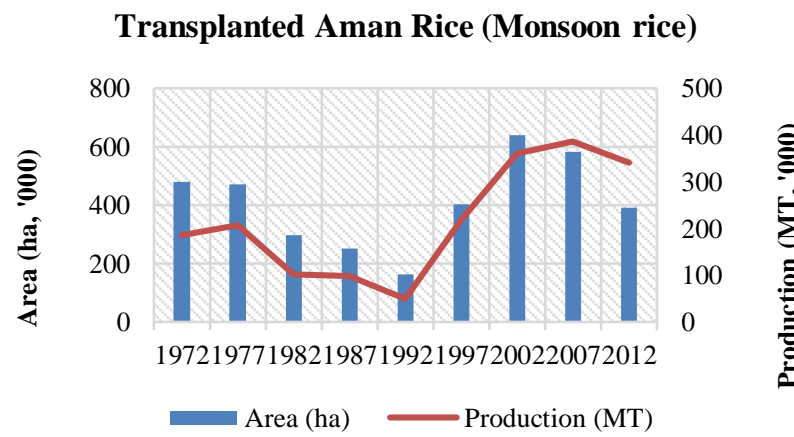

Fig 1. Trends of rice production over area and time in Bangladesh [27].

The smallholder farmers of Bangladesh apply unbalanced fertilizers in arable lands during the cultivation of crops without knowing the plant nutrient requirements. The soiltest based fertilizer application is limited due to lack of motivation and extension. The availability of some subsidized fertilizers (i.e. urea and triple superphosphate, potash) in rather cheaper rates during growing seasons also causes the application of higher rates of fertilizers. The farmers of Bangladesh traditionally believe since the introduction of high yielding varieties the application of more fertilizers may boost their crop yields. All these factors, in turn, caused the abundance of fertilizers in rice-based systems of Bangladesh with none or little application of organic manures. Therefore, to optimize fertilizer inputs and maintain soil fertility of arable lands it immensely important that farmers apply fertilizers according to the need for crops and based on the deficiency of plant nutrients in soils. In this regard, the location-specific online fertilizer recommendation (i.e. in this article identified as OFRS) could have great potential for application at farmer levels in Bangladesh. It is also equally important that fertilizer application should be optimized based on land qualities, type of crop, yearly cropping pattern and the residual effect of certain fertilizers require consideration for the recommendation of next crop fertilization. All these would be possible by the adoption and extension of OFRS for fertilization in Bangladesh. This would enable us to optimize input requirements (i.e. fertilizers) in Bangladesh. Therefore, this article synthesized the trend in fertilizer use, the balance of plant nutrients in soils in Bangladesh, and its variability due to smallholder farmer practices. 


\section{RESUltS AND DisCUSSION}

\section{A. Fertilizer use and rice yield in Bangladesh}

Submit your manuscript electronically for review. The fertility status of Bangladesh's soils is variable depending on major soil types in the different physiographic units. Soil constraints such as the depletion of organic matter, lower level of nitrogen, deficiency of micronutrients (e.g. zinc, boron), soil acidification in the northern districts, soil salinity in the southern districts are among the major issues related to the soils of Bangladesh [13]. More specifically, [14] reported Soil fertility status of intensive crop growing areas under major agroecological zones of Bangladesh; results indicated that soils are low in organic matter (1.1-1.7\%), deficient of nitrogen, low level of available phosphorus, sulfur, exchangeable potassium. Thus demanded the judicious management of soils for food security and to maintain soil fertility. Most of the soils are depleted and in urgent need of replenishment with manure, organic amendments, and balanced fertilizers if productivity has to be enhanced and maintain in the future. It is estimated that more than $100 \mathrm{~kg}$ of nutrients per ha year is being mined out from the soil system. Balanced fertilization is the key to successful crop production and maintenance of good soil health. More importantly, as in the rice-based systems of Bangladesh, the smallholder farmers practice, in general, double crops in medium highland and triple crops highland areas every year. Therefore a cropping pattern based fertilizer recommendation system would be the best fit to maintain soil fertility and achieve higher yields. However, the adoption of modern technology followed by high cropping intensity has caused the soils of Bangladesh to be deficient in organic matter and essential plant nutrients like nitrogen, phosphorus, potassium, and sulfur including the micronutrients [22]-[24], [14]. Extensive agricultural intensification with high yield goals and modern technology associated with higher use of inorganic fertilizers (Figure 2) are resulting in serious degradation of soil physicochemical properties, it has been reported that continuous and repeated use of inorganic fertilizers alone fails to sustain the desired yield, impairs the physical condition and reduces organic matter content of soils [25], [26]. In 1985-90, fertilizers contributed $25 \%$ to the total soil fertility whereas in $2010-15$ it increased to $40 \%$ indicating the degradation of soil fertility over time (Figure 3 ). The sole dependence of farmers in chemical fertilizers for increasing yields needs to be optimized to avoid the degradation of agricultural soils in Bangladesh. Hence, a good supply of organic matter through the incorporation of crop residues (although crop residue incorporation is traditionally limited to root biomass in Bangladesh) is essential for sustaining soil fertility and crop productivity. Overuse and underuse of chemical fertilizers can harm short term-yields and long-run sustainability of rice-based farming systems in Bangladesh. Inadequate fertilizer use where land is intensively farmed can strip nutrients from the soil, contributing to soil fertility degradation and threatening the farm's long-run sustainability. The overuse of fertilizer may result in a run-off that contaminates the local environment. Recommendations for fertilizer use are often based on regional (not location or plot-specific) soil and climate conditions, the fertilizer doses are also generic and therefore their use is limited both in terms of restoring soil fertility and maintaining desired yields.

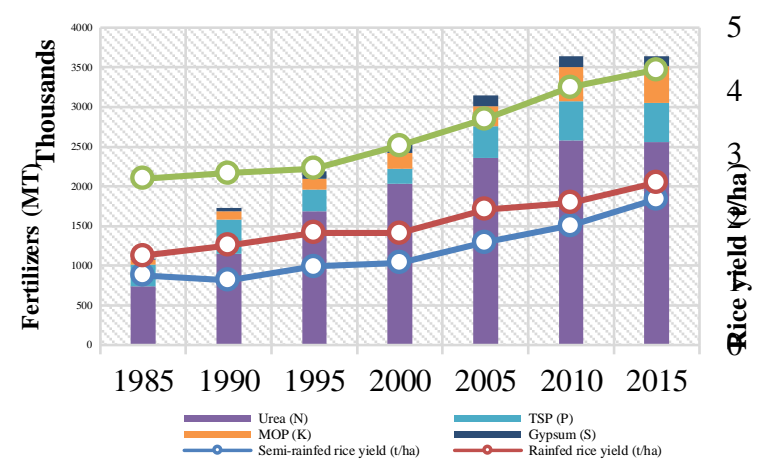

Fig 2. Fertilizer consumption and rice yields in Bangladesh over time (1985-2015) [27].

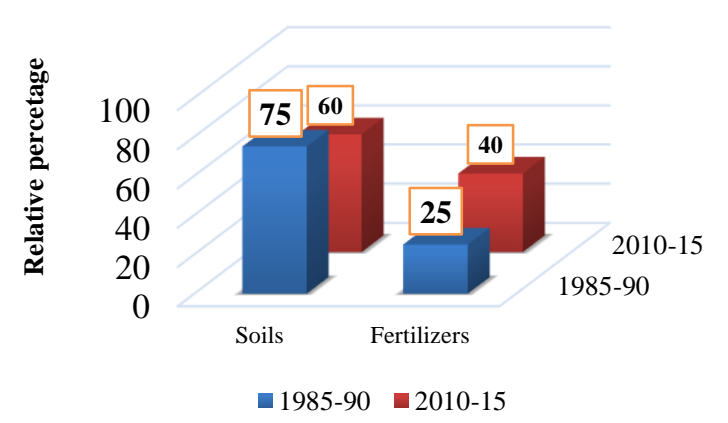

Fig 3. A hypothetical presentation of the relative contribution of soils and fertilizers on rice yield in Bangladesh.

\section{B. Trends in fertilizer use in Bangladesh}

When you submit your final version, after your paper has been accepted, prepare it in two-column format, including figures and tables. In past few decades, fertilizer has been a crucial component of the agricultural sector as value addition to Bangladesh Agriculture which is 'overwhelmingly' dominated by chemical fertilizers with a higher rate of the application over time (2002-2016) (Figure 4), and the double and triple cropping in the same piece of land in a year depleted the stock of nutrients. Besides, agricultural lands remain unable to replenish natural soil nutrients due to the intensive rice-based farming in Bangladesh. However, $40 \%$ of total food grains are directly attributed to fertilizer use and on average $80 \%$ of total fertilizer sales are used for paddy cultivation. At present, the major fertilizer being marketed in Bangladesh are urea (46\% nitrogen), triple superphosphate (TSP) ( $46 \%$ phosphate $/ \mathrm{P}_{2} 0_{5}$ ), single superphosphate (SSP) (14\%-18\% phosphate and $10 \%$ sulfur) and muriate of potash (MOP) $\left(60 \%\right.$ potash $\left./ \mathrm{K}_{2} 0\right)$. In addition, some ammonium sulfate (20\%-21\% nitrogen), gypsum (18\% sulfur), and Zinc (18\% sulfur and $36 \% \mathrm{Zn}$ ) are being marketed. Data indicates that urea dominates the fertilizer consumption in Bangladesh and urea also remains subsidized in the markets during the cultivation seasons (Boro rice and Aman rice) in Bangladesh [23] (Figure 2 and 5). 


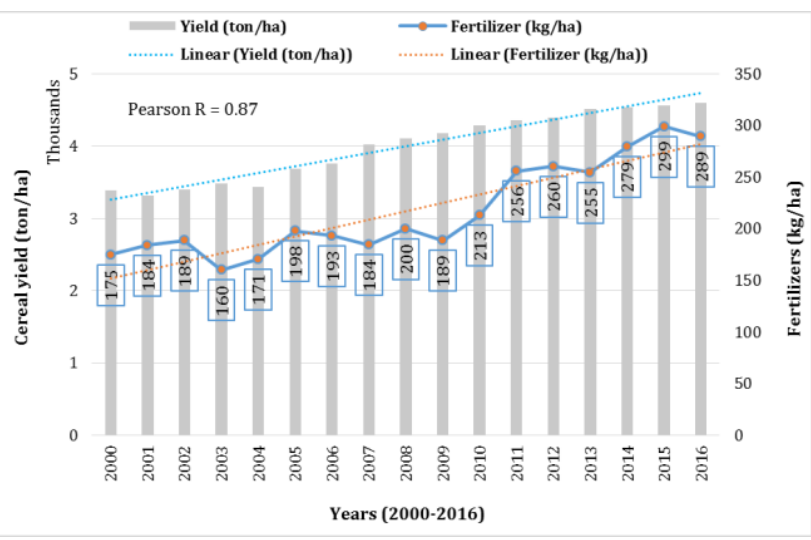

Fig 4. Fertilizers (kg/ha) and Yield (kg/ha) in Bangladesh from 2002 to 2016 (Source: World Bank, 2019).

\section{Fertilizer use: balance and challenge synergies}

The authors of the accepted manuscripts will be given a copyright form and the form should accompany your final submission. The increasing trend in unbalanced and excess fertilizer application per hectare of arable land throughout the cropping seasons was observed in Bangladesh. It is observed that the fertilizer consumption per hectare in Bangladesh is higher than the average and or optimum level in Bangladesh. Fertilizer application (kg/ha) and cereal yield (ton/ha) were found linearly related from the years 2002 to 2016 (Figure 4). During the same period, fertilizers $(\mathrm{kg} / \mathrm{ha})$ application ranged from $175-289 \mathrm{~kg} / \mathrm{ka}$ against the cereal average yield from 34 ton/ha (Figure 4). potassium and nitrogen ratio (K:N ratio) showed an upward trend indicating that the farmers remain positive as regards MOP use in crop production. However, The K:N ratio remains at around 0.1 . The low ratio indicates that the use of MOP fertilizer by the farmers might be far below as compared to recommended rates based on soil test status and crop requirement. As a result, all the research experiments based on major cropping patterns showed a negative balance of $\mathrm{K}$ in the soil [28]. This is also an example that farmers are not only applying the excess amount of urea fertilizer but also some fertilizers such as MOP is applied to an inadequate rate per hectare of land. This unbalanced application of fertilizers (i.e. some fertilizers applied in excess amount and some applied in low amount) is affecting the availability of soil nutrient unfavorably and deficiency of some plant nutrients is occurring in the agricultural soils of Bangladesh. Besides in some acidic soils of northern Bangladesh [3], due to the unavailability of phosphorus, the unbalanced bulk and unjustified farmer dose that is applied in soil remain unable to meet the $\mathrm{P}$ requirement of some crops such as potato. While MOP fertilizer is applied in higher doses during potato cultivation but its residual effect is not considered during the application of fertilizer in the next crop. The leftover and residual fertilizer in soils can potentially save input cost of farmers but this practice is limited in Bangladesh. Also, the farmers of Bangladesh are not aware of the importance of micronutrients (i.e. $\mathrm{Zn}, \mathrm{B}, \mathrm{Mg}$ ) application to boost soil fertility and crop productivity. For some crops such as wheat requires boron fertilizer for grain formation, maize requires magnesium, and zinc requires by many crops for growth and productivity. For all these reasons, it is highly significant and essential for soil-test based and cropping pattern based fertilizer recommendations for the rice-based cropping systems of Bangladesh.

\begin{tabular}{ccccccccccccc}
\multicolumn{1}{c}{ TABLE I: Estimated Nutrient Depletion In Major Cropping Patterns [13] } \\
\hline $\begin{array}{c}\text { Total } \\
\text { yield } \\
\text { Major cropping pattern }\end{array}$ & $\mathrm{N}$ & $\begin{array}{c}\text { Input } \\
\text { (t/ha/year) }\end{array}$ & & $\mathrm{K}$ & $\mathrm{N}$ & $\begin{array}{c}\text { Output } \\
\mathrm{P} \\
\mathrm{kg} / \mathrm{ha}\end{array}$ & $\mathrm{K}$ & $\mathrm{N}$ & $\begin{array}{c}\text { Balance } \\
\mathrm{P}\end{array}$ & $\mathrm{K}$ \\
\hline Boro-Fallow-T. Aman & 8.0 & 248 & 49 & 118 & 324 & 32 & 234 & -76 & +17 & -116 \\
Boro-T. Aus-T. Aman & 11.5 & 350 & 60 & 151 & 469 & 57 & 368 & -119 & +3 & -217 \\
Boro-GM-T. Aman & 8.0 & 285 & - & 135 & 324 & 32 & 240 & -39 & +28 & -105 \\
Mustard-Boro-T. Aman & 9.5 & 378 & 73 & 183 & 404 & 95 & 326 & -26 & -22 & -143 \\
Potato-T. Aus-T. Aman & 38.0 & 386 & 67 & 220 & 430 & 53 & 435 & -44 & +14 & -215 \\
Potato-Jute-T. Aman & 36.0 & 380 & 70 & 240 & 385 & 55 & 496 & -5 & +15 & -256 \\
Mustard-Jute-T. Aman & 7.5 & 340 & 75 & 205 & 430 & 79 & 429 & -90 & -4 & -224 \\
$\begin{array}{c}\text { Wheat-T. Aus-T. Aman } \\
\text { Wheat-Mungbean- T. }\end{array}$ & 10.0 & 335 & 65 & 166 & 420 & 64 & 292 & -85 & +1 & -126 \\
$\quad$ Aman & 8.0 & 275 & 64 & 190 & 305 & 52 & 284 & -30 & +12 & -94 \\
$\quad \begin{array}{c}\text { Sugarcane + Potato } \\
\text { intercropping }\end{array}$ & 100.0 & 190 & 55 & 150 & 210 & 60 & 320 & -20 & -5 & -170 \\
\hline
\end{tabular}

Plant nutrient balance for the major cropping patterns of Bangladesh is shown in Table 1. For all the cropping patterns, the balance of $\mathrm{N}$ and $\mathrm{K}$ is negative, while $\mathrm{P}$ balance is positive but to want extent this soil $\mathrm{P}$ is available for plants requires field-scale investigation. Balancing plant nutrients in the soil is essential for soil fertility.
The present level of fertilizer application is considerably below and or excess than the recommended dose for almost all food grains. Figure 5 indicates the percent fertilizer use gap between actual and recommended dose for all 3 major fertilizers applied in rice cultivation at farmers' level. Thus, there appears to exist a large potential for raising fertilizer consumption through the adoption of the recommended 
fertilizer practices by farmers [29].

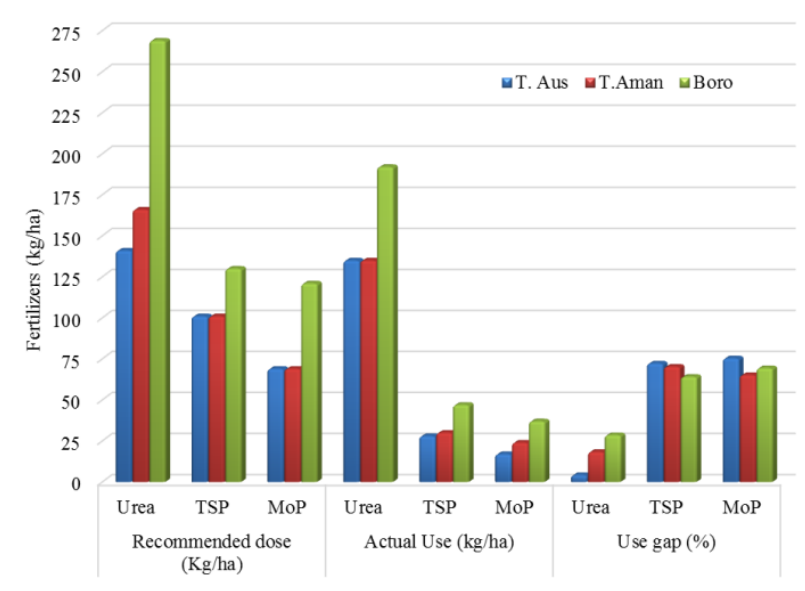

Fig 8. Fertilizer use gap in Bangladesh [13]

\section{ICT and its current status in Bangladesh}

Globally, the development of Information and Communication Technology (ICT) has proven its potentials for enhancing development efforts, but also virtually reduced the distance and turned the world into a global village [30]. Worldwide, ICTs are playing a vital cross-cutting enabler role to address many problems. Although the computer was introduced in Bangladesh more than 50 years ago, the application of ICT in agriculture was initiated only in 1979. A major ICT initiative was taken from 1979-1985 to computerize the Reconnaissance soil survey information generated through a UNDP/FAO funded project during the period from 1963 to 1975 , which is known as the Land Resources Appraisal of Bangladesh. As a follow up of this, several ICT initiatives/programs were undertaken and the outputs of these were used for agricultural research, development and extension, and disaster management. Services are being provided to the Ministry of Agriculture and other Ministries, various National Agricultural Research System (NARS) institutes, various extension agencies, Universities, International Organizations, and GOs and NGOs by catering to their needs.
E. Soil information and fertilizer recommendation: an institutional approach

\section{SOLARIS: Soil and Land Resource Information System}

Soil Resources Development Institute (SRDI) in collaboration with CEGIS, a not-for-profit Geographic Information System (GIS) based research organizations, developed a massive 2GB database that stores soil data using primary information from Upazila Nirdeshika. The system is called 'The Soil and Land Resource Information System' or SOLARIS. Customized GIS software SOLARIS-GIS is also developed to map soil data based on classification (Soil Texture, Land type, Landform, Drainage, Slope, Surface Water Recession) and condition (Crop Suitability, Land Zoning, Nutrient Status and Fertilizer Recommendation). The system can analyze data at the Upazila (sub-district), District, and National levels. Given the current context of Bangladesh, the system has a wide range of potential use and benefits. Solaris startup windows is as follows (Figure 6).

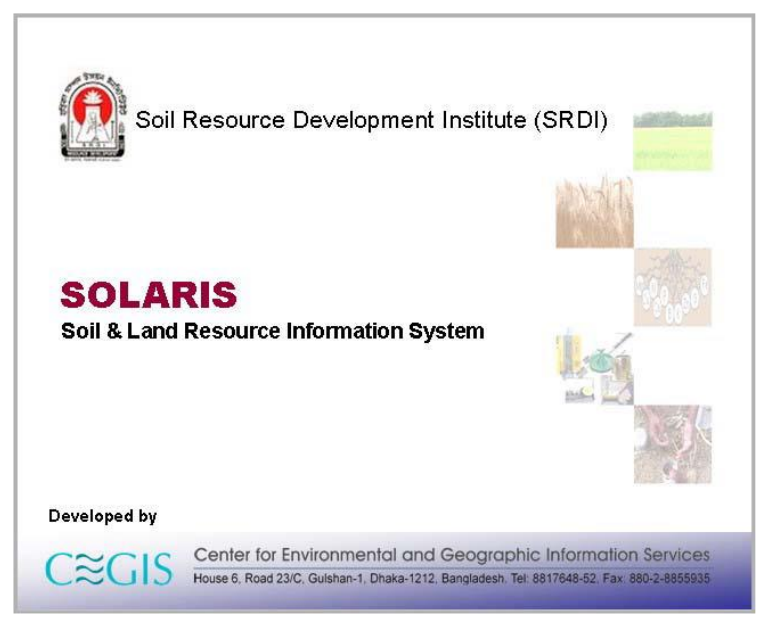

Fig 6. Screenshot of SOLARIS starts up window.

These satellite-based precision maps can assist the farmers to determine the optimal use of fertilizer for each type of crops in each season and thereby reducing the cost for the farmer and limit environmental hazards from unplanned usage [31]. The analysis is integrated with the SOLARIS Data Interpreter (Figure 7). Users can analyze and give feedback to the GIS unit for updating. Users can view, print reports, and charts. Further information on SOLARIS can be collected by contacting SRDI, Bangladesh.

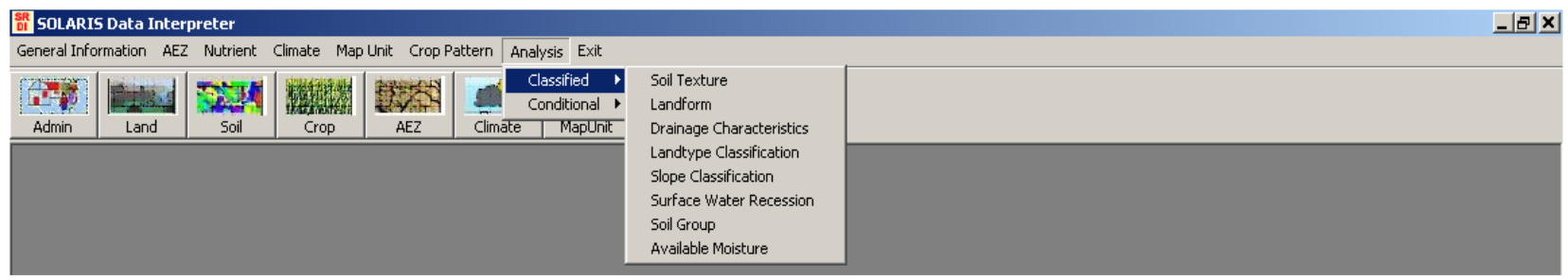

Fig 7. Screenshot of SOLARIS data interpreter in Bangladesh.

\section{Online Fertilizer Recommendation System: OFRS}

To increase crop production, reduce misuse of fertilizer, reduce crop production cost by reducing the current practice of using excessive fertilizer, and maintaining soil fertility the Soil Resource Development Institute (SRDI) used to provide location-specific fertilizer recommendations through the manual interpretation of its national nutrient database. SRDI in collaboration with KATALYST (a Foreign NGO) developed web-based software named Online Fertilizer Recommendation System. The OFRS can be accessed online in the web address: http://www.frs-bd.com/. The system is capable of generating location-specific fertilizer recommendations for selected crops by analyzing the national nutrient database developed by the institute [8]. The service 
European Journal of Environment and Earth Sciences www.ej-geo.org

delivery process of fertilizer recommendation software using digital channels is as follows (Fig. 8 and 9).

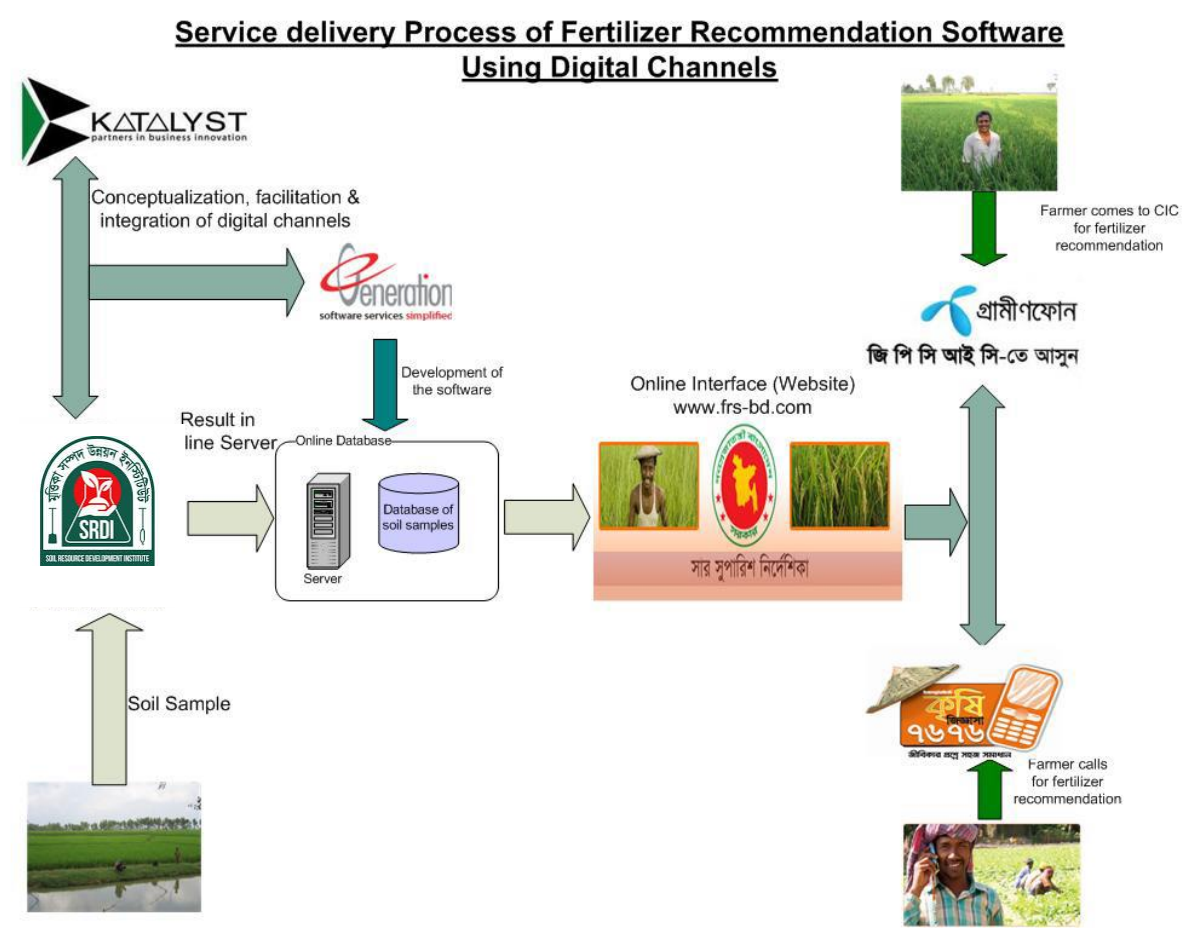

Fig 8. Screen snapshot of the service delivery system.

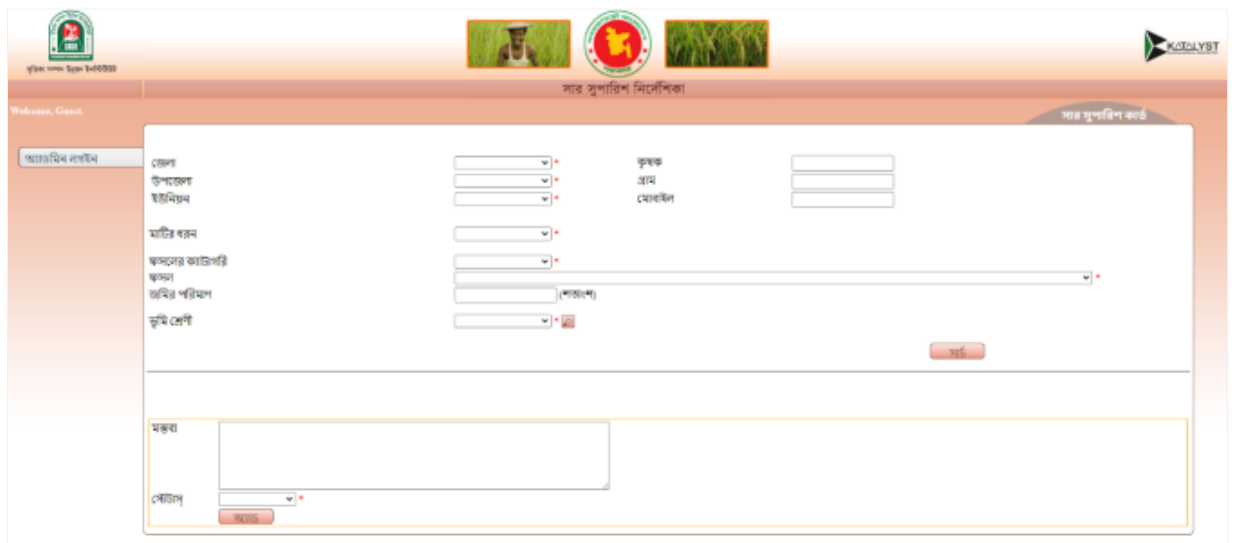

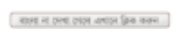

Fig 9. Screen snapshot of Fertilizer Recommendation Menu in OFRS system.

The Software has an inbuilt service delivery monitoring system called CRM [Customer Relation Management]. CRM keeps a record on Login history, Fertilizer recommendation service history with name, location, contact number of service receiver/farmer, land type, crop name, date, the quantity of land etc. The total number of farmers used OFRS for fertilizer recommendation service is 56, 293 since inception in 2009 [32].
Farmers are benefitted by using balanced fertilizer on the basis of OFRS database. It is a low/no-cost technology through which farmers can get a higher yield of crops. It is observed that farmers got $7 \%$ to $22 \%$ increase in yield in different rice varieties in different locations and seasons [32]. These yield trials were conducted by the different district offices of SRDI, Bangladesh.

\begin{tabular}{|c|c|c|c|c|c|c|}
\hline \multirow[b]{2}{*}{ Name of Upazila } & \multirow[b]{2}{*}{ District } & \multirow[b]{2}{*}{$\begin{array}{l}\text { Cropping } \\
\text { season }\end{array}$} & \multirow[b]{2}{*}{ Variety (Paddy) } & \multicolumn{3}{|c|}{ Yield (t/ha) } \\
\hline & & & & $\begin{array}{c}\text { Farmer's } \\
\text { plot }\end{array}$ & $\begin{array}{c}\text { Demo } \\
\text { plot }\end{array}$ & $\begin{array}{c}\text { Increase } \\
(\%)\end{array}$ \\
\hline Fakirhat & Bagerhat & Kharif-2 & BRRI dhan52 & 3.2 & 3.9 & +21.9 \\
\hline Bagerhat Sadar & Bagerhat & Kharif-2 & BRRI dhan52 & 3.8 & 4.2 & +10.5 \\
\hline Fakirhat & Bagerhat & Kharif-2 & BRRI dhan 49 & 3.9 & 4.3 & +10.3 \\
\hline Jessore Sadar & Jessore & Kharif-2 & BRRI dhan49 & 4.2 & 4.7 & +11.9 \\
\hline Jessore Sadar & Jessore & Robi 2017 & BRRI dhan28 & 5.4 & 6.2 & +14.8 \\
\hline Monirampur & Jessore & Robi 2017 & BRRI dhan28 & 5.5 & 5.9 & +7.3 \\
\hline
\end{tabular}




\section{CONCLUDING REMARKS AND FUTURE IMPLICATIONS}

Population explosion and the need to provide food for humankind and to increase the quality and quantity of food products to ensure food security concerning its managerial, environmental, and developmental aspects has led to the use of new agriculture methods and technologies. Today, fertilizers have a very significant impact on the world's food supply; Bangladesh is not different from this concept considering its growth in population and rising demands for food. The major fertilizers used in the food production cycle contain phosphorus, nitrogen, and potassium as the main nutrients in agricultural fields in Bangladesh. The usage of fertilizers shows an increasing trend in Bangladesh in the past decades. But the rate of application is higher and or lower, not at optimum required levels, the amount of fertilizer applied is variable depending on the practice of farmers, locality, and seasonal availability. More importantly, farmers apply fertilizers in the unbalanced dose and do not follow the cropping pattern based fertilizer application. Neither most farmers apply necessary micronutrients for plants in soils. Soil-test based application of fertilizer is limited due to the lack of motivation of farmers and extension activities. Besides the benefits of using fertilizer to increase crop yield in the agricultural production system, in many cases, excessive use or abuse of fertilizers has caused problems, such as poor product quality and a decline in productivity. The use of such unbalanced fertilizers creates a spatial variation of plant nutrients based on crop and soil conditions and cause a decline in soil fertility. Combined application of recommended nutrients using organic and inorganic sources in soils could be considered as one of the best management practices in sustainable agriculture of Bangladesh. It was observed that more and more farmers are using the OFRS for getting a recommendation for crops of their choice and getting higher yields. The online fertilizer recommendation system has been serving as a tool to transform to precision agriculture in Bangladesh concerning optimized fertilizer use and maximizing yield from crops. The OFRS system requires further promotion and effective extension, so that community and rural level smallholder farmers throughout the country get themselves encouraged using the online fertilizer recommendation for fertilizer application in Bangladesh.

\section{REFERENCES}

[1] Hossain, M. A., Amin, M. N., Sultana, J. and Siddique, M. N. A. "Climate Change Impact on Agriculture and Related Sustainable Land Management Practices in Bangladesh-A Review," International Journal of Environment and Climate Change, 10(2): 53-69, 2020.

[2] Sultana, J., Siddique, M. N. A., \& Abdullah, M. R., "Fertilizer recommendation for agriculture: practice, practicalities and adaptation in Bangladesh and Netherlands," International Journal of Business, Management and Social Research, 1(1), 21-40, 2015.

[3] Sultana, B. S., Mian, M. H., Jahiruddin, M., Rahman, M. M., Siddique, M. N. E. A., \& Sultana, J., "Amendment of Acidic Soil with Lime and Manure for Enhancing Fertility, Nutrient Uptake and Yield of WheatMungbean-Monsoon Rice in the Old Himalayan Piedmont Plain," Asian Journal of Soil Science and Plant Nutrition, 1-26, 2019a.

[4] Sultana, B. S., Mian, M. H., Jahiruddin, M., Rahman, M. M., Siddique, M. N. E. A., \& Sultana, J., "Liming and Soil Amendments for Acidity Regulation and Nutrients Uptake by Potato-Mungbean-Rice Cropping
Pattern in the Old Himalayan Piedmont Plain," Asian Journal of Agricultural and Horticultural Research, 1-15, 2019b.

[5] Siddique, M. N. A., Sultana, J., Abdullah, M. R., \& Azad, K. N., "Modelling of Soil Loss through RUSLE2 for Soil Management in an Agricultural Field of Uccle, Belgium," British Journal of Environment \& Climate Change, 7(4): 252-260, 2017

[6] Siddique, M. N. A., Sultana, J., \& Abdullah, M. R., "Aggregate stability: an indicator of quality and resistivity of arable Soil," Asian Journal of Soil Science and Plant Nutrition, 1-7, 2017a

[7] Siddique, M. N. A., Halim, M. A., Kamaruzzaman, M., Karim, D., \& Sultana, J., "Comparative insights for investigation of soil fertility degradation in a piedmont area which cover the Anjamkhor Union of Baliadangi Upazila, Thakurgoan, Bangladesh." Journal of Environmental Science, Toxicology and Food Technology, 8(4), 82-87, 2014.

[8] Klaus D. and Derek B. with Jonathan L., Andrew N., Harris S., and Mercedes S. edited. "Rising Global Interest in Farmland can it yield sustainable and equitable benefits?" Agriculture and rural development, World Bank, 2011.

[9] World Bank, 2019. "Fertilizer and yield Data of the World Bank", Retrieved 25 March 2020 from https://data.worldbank.org/indicator/AG.CON.FERT.ZS?view=chart

[10] Hossain, M. A., \& Siddique, M. N. A., "Water-A limiting resource for sustainable agriculture in Bangladesh," EC Agriculture, 1(2), 124-137, 2015.

[11] Rahman, S., "Six decades of agricultural land use change in Bangladesh: Effects on crop diversity, productivity, food availability and the environment, 1948-2006," Singapore J. of Tropical Geography 31, 2, 254-269(16), 2010.

[12] David, E., N. Clay, K. Kithen, C. Greeg, J. Klenjal and G. Chang, "Using historical management to reduce soil sampling errors." In: GIS Application in Agricultural, Bulgarian Journal of Agricultural Science 21(3), 53-69, 2015.

[13] FRG (Fertilizer Recommendation Guide), "Fertilizer Recommendation Guide," Bangladesh Agriculture Research Council (BARC), Farmgate, Dhaka 1215, 2012

[14] Shil, N. C., Saleque, M. A., Islam, M. R., \& Jahiruddin, M., "Soil fertility status of some of the intensive crop growing areas under major agroecological zones of Bangladesh," Bangladesh Journal of Agricultural Research, 41(4), 735-757, 2016.

[15] Moslehuddin, A. Z. M., S. Laizoo and K. Egashira, "Fertility Status of Bangladesh Soils -A Review,” J. Fat. Agr., Kyushu Univ., 41 (3.4), 257-267, 1997

[16] Siddique, M. N. A., "Determination of N mineralization, total $\mathrm{N}$ and cation exchange capacity of soil through NIR spectroscopy for decision support in rice farming," International Journal of Business, Management and Social Research, 1(01), 47-50, 2015

[17] Siddique, M. N. A., Islam, M. M., Sultana, J., Kamaruzzaman, M., \& Halim, M. A, "Potential of soil sensor EM38 measurements for soil fertility mapping in the Terrace soil of Bangladesh," Journal of Science, Technology and Environment Informatics, 1(01), 01-15, 2014

[18] Huq, S. I. and Shoaib, J. M. (2016). The soils of Bangladesh, Springer.

[19] World Bank, Bangladesh: Growing the Economy through Advances in Agriculture," www.worldbank.org/bangladesh, 2016

[20] FAOSTAT, Food and Agricultural Commodities Production," Rome, Italy: FAO: 2012. 2010 http://faostat.fao.org 4 November 2012, 2007.

[21] GAIN, Grain and Feed Annual Bangladesh, GAIN Report Number: BG30043/28/20132013, 2013

[22] Hoque, M. S. and Jahiruddin, M., "Effect of single and multiple applications of sulfur, and Zinc in a continuous rice cropping pattern," Indian Journal of Agricultural Research, 28(1): 9-14, 1994

[23] Karim, Z., Miah, M. M. U. and Razia, S., "Fertilizer in the National Economy and Sustainable Environmental Development," Asia Pacific Journal on Environment \& Development, 2:48-67, 1994.

[24] Ali, M. M., Saheed, S. M., Kubota, D., Masunaga, T. and Wakatsuki, T., "Soil degradation during the period 1967-1995 in Bangladesh," Soil Science \& Plant Nutrition, 43: 863-890, 1997.

[25] Singh, H., Verma, A., Ansari, M. W. and Shukla, A., "Physiological response of rice (Oryza sativa L.) genotypes to elevated nitrogen applied under field conditions," Plant Signaling \& Behavior, 9 (7) 29015, 2014.

[26] Ali, M. E., Islam, M. R., and Jahiruddin, M.. "Effect of integrated use of organic manures with inorganic fertilizers in the rice-rice cropping system and its impact on soil health," Bangladesh Journal of Agricultural Research, 34(1): 81-90, 2009

[27] BBS, "Agricultural Yearbook 2015," Bangladesh Bureau of Statistics, Statistics Division, Ministry of Planning, Government of People's Republic of Bangladesh, Dhaka, 2015. 
[28] O'Farrell, C., Global Trends and Major Issues of ICT Application in Agriculture Paper presented at APO seminar on Information and Communication Technology (ICT) for improved Agricultural Productivity and Competitiveness, held in Yogyakarta, Indonesia, during 8-12 September 2003.

[29] MOA, Handbook of Agricultural Statistics, Market Monitoring and Information System. Ministry of Agriculture, Govt. of the Peoples Republic of Bangladesh, 2007.

[30] BARC, Priority Setting Reports Agricultural Research priority: Vision beyond 2030 Sub-sectoral study on ICT in Agriculture and Disaster Management," pp 45-46, 2010

[31] UNDP, United Nations, Department of Economic and Social Affairs, Population Division (2013), World Population Prospects: The 2012 Revision, Highlights and Advance Tables, Working, Paper No. ESA/P/WP.228.

[32] SRDI, Annual Report, Soil Resource Development Institute (SRDI), Ministry of Agriculture, Bangladesh 2009-10, 2010. 